\title{
EDITORIAL
}

\section{CONDITIONS NOW, AND AFTER PEACE IS DECLARED.}

$\mathbf{N}^{\circ}$

retail business has been more disadvantageously affected by higher costs than the drug business, one of the reasons being that there have been comparatively few changes in retail selling prices for many years. A few items, perhaps, have in the past fluctuated sufficiently to make a change in selling prices necessary, but now nearly every drug item is largely affected.

The very unusual situation obtains that a prescription filled to-day may cost decidedly more to-morrow, and in justice to themselves pharmacists are compelled to exact their usual profit. Nearly everywhere publicity has been given, so the public is informed.

The high prices have tempted sophistication, substitution and adulteration, and in some instances such fraudulent practices have been carried so far as counterfeiting the labels of reputable manufacturers and thus fleecing the unwary druggist. This teaches the lesson that retailers themselves impress upon their patrons, namely, that reputation is one of the valuable assets of pharmacists. Attractive prices have in some instances blinded the precaution of retailers, which they should exercise in buying, for the tests which are provided by the Pharmacopcia are suffcient for detecting the gross substitution and adulteration resorted to. Hence, it must be admitted that in some of the cases which have come to public notice, the purchasers were not altogether blameless.

No one need be told that conditions now are abnormal, and it is for this reason that every citizen is interested in what normal conditions will be after peace is declared ; certainly they will not be the same as those that obtained before the warthe readjustment in many lines will present serious problems.

As far as the drug business is concerned, there should be a possibility of profiting by experience; it is probably advisable to be judicious in buying. Speculation has entered largely into the advances of prices, for many articles are really not now affected by demand or lack of supply; however, the fact remains that there is an interrelation between many crudes and manufactured products; limited uses for some things have become extensive and we have found that certain drugs have a far larger application in other lines than ours. To be more specific, the various substances that enter into the manufacture of explosives are quite generally known, so that the high price of glycerin, sulphuric and nitric acids creates no surprise; but these and the constituents for production are also required for other manufacturing, therefore numerous articles are affected in price. Castor oil is used extensively in the leather industries and also as a necessary lubricant for aeroplanes; by far the larger amount of licorice is consumed by the tobacco 
industries, etc. So the links of the chain that have compelled higher prices become evident. With all of that the potential factor is, that the United States is being called upon to supply the world, which sends prices skyward, and in this way we are paying part of the cost of war in Europe, though through other sources than ours the money is coming back.

In the sections of the country where war supplies are manufactured, the cost of labor has advanced, affecting every other line; when peace comes there must be a readjustment and our further foreign trade will largely depend on the attitude of labor, for Europe will be trying to recapture the trade our manufacturers have won. As Frank A. Vanderlip says, we certainly have a better chance to connect. up our industries with world trade and world development than ever before, but the fact that one man has a better chance than another, or one nation has greater natural advantages than another, has never yet determined the result of competitive struggle. We cannot rest on a level of cost of production far above the rest of the world and hold our place in the sun.

But to come back to that which concerns us more directly: As far as possible we should establish an American materia medica. It is not implied that proven remedies should be discarded, but heretofore we have depended on Europe's research work, with the result that the medicinal products were manufactured there. We have further protected them by American patents, to our own disadvantage. The recipient of such protection should be called upon to manufacture in this country, if he would enjoy special privileges. Under no circumstances should it be possible to charge us one dollar for what an adjoining country pays only twenty cents. Another condition that may obtain is that in order to discourage American manufacturers, who contend with higher labor cost, European manufacturers may unload large stocks here at low prices.

We have always suffered from high cost of waste, and if our experience will point the way to thrift we will be the gainers. Every state should look into its natural resources and waste products. Plants yielding drugs that we have been importing grow and die, while if the farmers knew them, they might be collected. Nany manufacturing establishments have waste material that ought to be converted into useful products.

In every locality meetings of physicians and pharmacists should be held for discussion of the present status of the drug market. The physicians have become wedded to certain therapeutic agents that could readily be displaced; for example, sodium salts for those of potassium, the use of galenicals for active constituents, etc. Physicians should acquaint themselves with the Pharmacopcia and National Formulary and then decide what, in their opinion, they must have, and thereafter pharmacists can offer suggestions for consideration. A careful survey and coöperative study will do much toward relieving the present trying situation and prepare us for utilizing coning opportunities.

E. G. E. 


\section{PROPAGANDA OF PHARMACY IN THE STORE.}

THERE should be a time for inspection and perspection for pharmacists. They should sometimes step on the outside and look in. Pharmacy has a mission, but its potency is lessened when the armamentarium is obscured by the multiplicity and diversity of stock; a cause is often weakened by an explanation and injured by an apology.

Side-lines are essential in the modern drug store for increasing the volume of business and profits, but the pharmacy should be kept separated from that part of the stock in the store. Let it be a pharmacy in a drug store, if nothing more is possible. The public receives a wrong impression of what pharmacy means when the sundry assortment is displayed and arranged with materia medica.

Gifts and sundry items are articles of merchandise that can be sold advantageously in a drug store, should be advertised and displayed according to modern store methods whereby such sales are promoted, but let pharmacy have an opportunity to represent itself without detracting from its mission.

We should be honest with ourselves and with the public; no success was ever permanent that required the obscuring of something, that compelled an apology. If, in order to preserve the success of those engaged in the drug business, merchandizing is essential, let us be frank and admit it ; certainly business conducted on the high plane of modern ideas is honorable and not something to be ashamed of. Make-believe is harmful, whatever its association may be.

Another thought: How can sellers of medicines excuse themselves when they are purveyors of harmful preparations, of those that are not what they purport to be, and the sales of which are established by high-sounding and persuasive argument, but not applicable in fact to the preparation advertised? The encouragement of such traffic cannot contribute a service which will establish pharmacy on a firmer foundation.

We do not advocate counter-prescribing, but just for the sake of thoughtful consideration, would the public be better served or not, if, instead of some of the preparations referred to, know'n to be either inefficient or dependent for effect on the stimulant contained therein alone, they would be persuaded to purchase a preparation made by the pharmacist, and not of the former type?

As a matter of fact, would not such action be the lesser offence, and would this not finally educate the public to consult physicians when necessary, even though for minor ailments they continued to purchase the remedies prepared by the pharmacists? Would not medicine and the public benefit thereby?

Of course, here comes the old familiar question: Am I my brother's keeper? Counter-prescribing is often looked upon from a very restricted viewpoint-the sales of proprietary medicines constitute, at least occasionally, a like offence as the suggestion of simple remedies prepared in the pharmacy.

Aside from the thought relative to what portends the best service, this writing is intended to stimulate a deeper interest, if possible, in applying the work of 
pharmacists and physicians who seek to devise standards for drugs and representative formulas for preparations of them.

In a way, physicians have similar problems. Take the patient who expects a prescription but really needs no medicine. While from one point of view, the physician should so advise the patient, in many instances this would create dissatisfaction. If a sensible person were told that the medicine would have no effect on the malade imaginaire except through the mind, he would doubtless retort, "What sort of a fool do you think I am?" It is only because the real intentions are concealed that the patient in confidence takes the medicine. But patients are not born with the belief that every symptom must be counteracted by a drugthey acquire that belief by persuasion. So, after all, this is a form of quackery.

The public will gradually become educated along both lines, and during the meantime it is certainly advisable to act according to moral dictates and rational practicability and with progressive forethought. The disclosures after the Federal Food and Drugs Act became effective are not too remote for reference; the very fact that harmful and misleading preparations were sold did not give the public greater confidence in those who knowingly, or otherwise, promoted such sales.

This, then, is a call for bringing into more extended use the preparations of the Pharmacopoia and National Formulary. We are all interested in developments that will elevate pharmacy and enable pharmacists to render better service; so even these suggestions may be helpful if, when applied, they will make pharmacists worth more to themselves and worth more to others.

E. G. E.

\section{THE ORIGINAL CERTIFICATE OF MEMBERSHIP OF THE} AMERICAN PHARMACEUTICAL ASSOCIATION.

At the meeting of the American Pharmaceutical Association, held in Boston August 24 to 26, 1853, a committee was appointed " to inquire into the expediency of obtaining a form of certificate of membership for the use of the Association, with such insignia and devices, or otherwise, as shall in their opinion be suitable." The members of this committee were Andrew Geyer of Boston, Charles Ellis of Philadelphia, and Joseph Laidley of Richmond.

A report of the committee was made at the session held in Cincinnati in 1854, and the Association gave instructions for further report to be presented at the annual meeting held in New York in 1855. In the meantime, the chairman, Mr. Geyer, had died and the report was made by Charles Ellis, and thereafter William Procter, Jr., was named a member of the committee in place of the deceased, and John Meakim of New York was added to the committee.

The final report and presentation of certificate were made at the fifth annual meeting, held in Baltimore, September, 1856, and therein the certificate was described. We are using the words of the report for the description and presenting a 
reduced cut of the certificate of Dr. John F. Hancock, Baltimore, chairman of the William Procter, Jr., Monument Committee.

" Near the centre of the picture is a monument in honor of Pharmacy, consisting

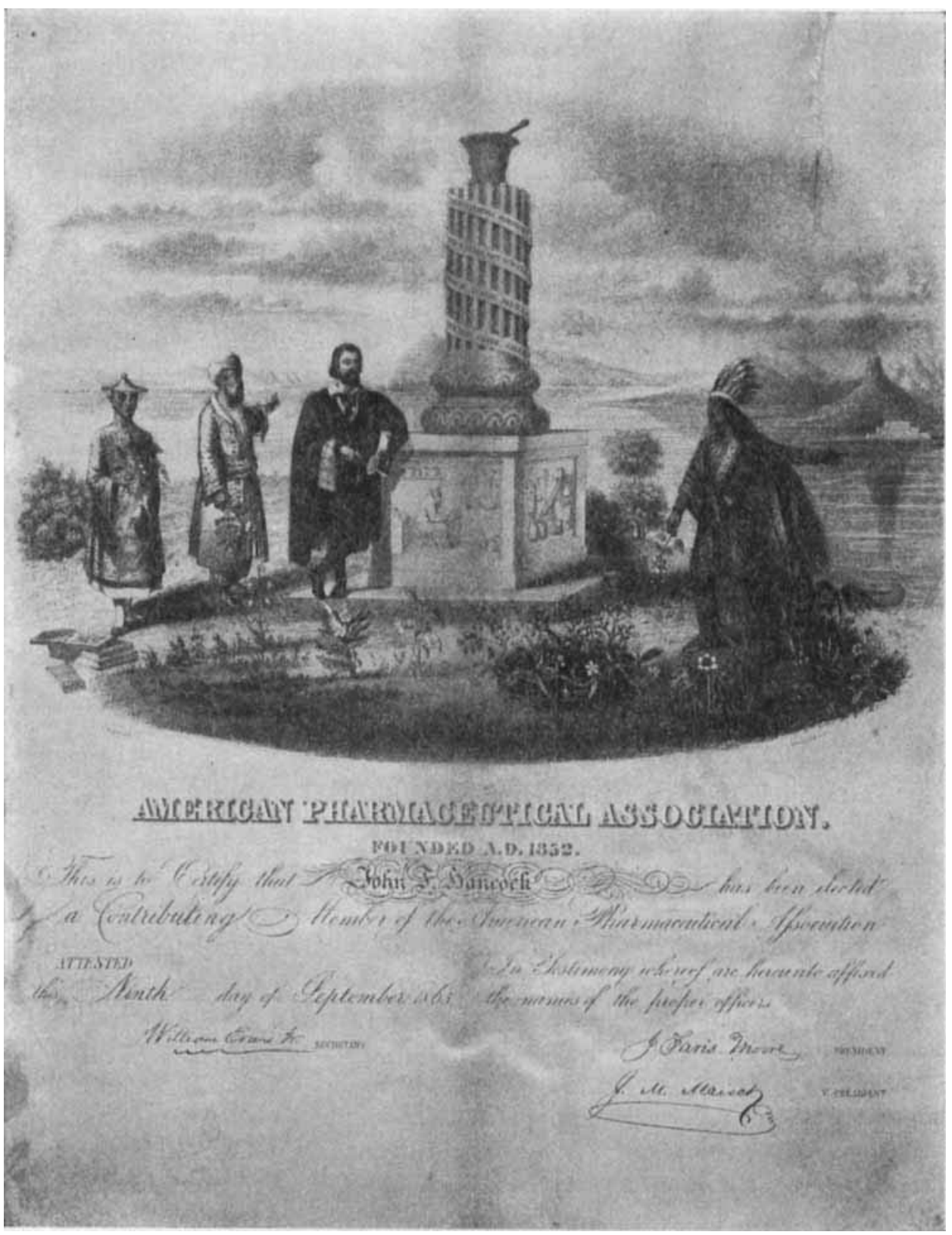

CERTIFICATE OF MEMBERSHIP OF JOHN F. HANCOCK. BALTIMORE

of a square panelled base, from which rises a fluted column, surmounted by the mortar and pestle. Encircling the shaft of the column is a winding scroll, on which appear the names of Galen, Geber, Avicenoa, Bazil Valentine, Lemery, 
Baumé, Scheele, Davy, Sertuerner, Robiquet, Pereira and Liebig. One of the panels represents an alchemist at his furnace, the other exhibits a series of pharmaceutical apparatus, the balance, gas burners, Liebig's condenser, graduated measure, 1000-grain bottle, etc. There are four human figures: a European, a Turk, a Chinese, and an American Indian. The European is leaning gracefully with his left arm on the monument, with a book (the Pharmacopoia) in his left hand, whilst his index finger points toward the Structure. The Turk holds in his right hand the Poppy and Acacia vera, whilst his left is extended toward the horizon, where a group of pyramids symbolizes the East. The Chinese holds in his right hand the Laurus camphora and Piper nigrum, whilst at his feet is a pile of Chinese books, towards which he points. The American Indian, on the right of the picture, is represented as in the act of speaking, with a branch of cinchona in his right hand, and his left extended toward the south, indicated in the horizon by a volcano (Cotopaxi) in the Andes, and by a Mexican teocalli. Before him, on the ground, is a rude wicker basket containing a variety of plants from Southern America, among which may be recognized ipecacuanha, cinchona, quassia, angustura, copaiba, guaiacum, canella, sarsaparilla and jalap, whilst around him, growing from the soil, are several well-known North American plants, as senega, spigelia, sanguinaria, podophyllum, etc.

The explanation of the picture is as follows: The European represents the scientific pharmacy of all countries; every region contributes to its materia medica; and his scientific art, illustrated by the illustrious individuals named on the column, has votaries in every country where European civilization has extended, without reference to nationality. The Arabian symbolizes that imperfect empyrical pharmacy that pertains to Mohammedan countries. The Chinaman signifies that ultraoriental pharmacy now practised in India, China, and Japan, embraced in the volumes before him, and which he boasts as antedating the earliest records of European science. The Indian is introduced to Americanize the picture. $\mathrm{He}$ is represented as saying, however valuable are the plants growing around him, and with the virtues of which he is familiar, those given by the Great Spirit to his aboriginal brethren of tropical America, of which the basket contains a sample, are far more important and useful.

One of the reasons for discontinuing this certificate was the use of the design by a proprietary medicine manufacturer. 